\title{
INTEGRATING ANIMATION INTO TEACHING COMPUTER SIMULATION
}

\author{
Kambiz Farahmand, Satpal Singh Wadhwa, Mahmoud Mostafa \\ North Dakota Sate University, $141014^{\text {th }}$ Ave. North, Fargo, ND 58102 \\ Kambiz.farahmand@ndsu.edu \\ North Dakota Sate University, $141014^{\text {th }}$ Ave. North, Fargo, ND 58102 \\ satpalsingh.wadhwa@ndsu.edu \\ North Dakota Sate University, $141014^{\text {th }}$ Ave. North, Fargo, ND 58102 \\ mahmoud.mostafa@ndsu.edu
}

\begin{abstract}
Computer simulation is an experiment using a computer model to represent a unique system. Variables are defined and parameters to be study are monitored and recorded. Growing capabilities and decreasing costs of microcomputers are placing this powerful tool at the fingertips of scientists and engineers. In the past, the use of digital computers in simulation required a considerable amount of programming effort. This is no longer a true statement.

Simulation provides the student with a greater breadth and depth of information on which decisions could be made. It is also considered one of the most valuable and flexible decision making tools available. Flexible simulation and animation models developed using a multitude of software's available in the market today is considered a very powerful and effective approach in engineering education. Simulation and animation models could easily be used to solve complex and dynamic problems in both the classroom and real life.

Computer simulation techniques and soft wares have been used for more than a decade to help engineers in development, trouble shooting, problem solving, and decision making process. The new paradigm in computer simulation is the use of animation and virtual reality to build engineering models and animation, simulate operations and performance. The fantastic progress in computer hardware and software industry has now opened a new and higher level of teaching computer simulation.
\end{abstract}

\section{Indexing terms/Keywords}

Computer Simulation, Animation, Virtual Reality

\section{Academic Discipline And Sub-Disciplines}

Business, Manufacturing, Industrial Engineering:

\section{SUBJECT CLASSIFICATION}

Computer Simulation Classification;

\section{TYPE (METHOD/APPROACH)}

Research in Modeling and simulation of real-world processes and activities;

\section{Council for Innovative Research}

Peer Review Research Publishing System

\section{Journal: International Journal of Research in Education methodology}

\section{Vol. 7, No.3}

ijremeditor@gmail.com

www.ijrem.com 


\section{INTRODUCTION}

The role of simulation is to evaluate practical alternatives either in support of major strategic initiatives which might involve a large financial investment, or in support of the continuous search for continuous improvement at operational and tactical levels. Examples of such evaluations include changes to the product mix, increases or decreases in production volumes, improvements in throughput, shorter lead times and improve customer response times. Simulation provides the students with a greater breadth and depth of information on which to base decisions: it is not an optimizing tool. It is capable of handling the complexity of large systems.

Visual Interactive Simulation has features for graphical creation of simulation models, dynamic display of the simulated system and user interaction with the running program. Interaction implies that the simulation halts and requests information from the user, or the user stops the simulation at will and interacts with the running program (Hurrion 1986).

Microcomputers and associated software have brought the power of management science techniques and models to the fingertips of engineers and even managers for everyday decision making. The application of simulation is a powerful technique to solving and uncovering satisfactory solutions to difficult problems.

\section{COMPUTER SIMULATION}

In its broadest sense, computer simulation is the process of designing a mathematical/logical model of a real system and experimenting with this model on a computer. Thus simulation encompasses a model building process as well as the design and implementation of an appropriate experiment involving that model. These experiments, or simulations, permit inferences to be drawn about systems and their operation without actual construction of the system. The simulation model could be modified for various experiments without costly, unsafe, and destructive procedures. In this way, simulation models can be used for design, procedural analysis, and performance assessment.

The student's response to the use of discrete or continuous event simulation using both programming language and a flexible simulation and animation package has been unprecedented. From the beginning, programs such as SLAM, SIMAN, SIMFACTORY, FLEXSim, ARENA, WITNESS, TAYLOR, and Simio among others have been utilized to familiarize students to simulating real life problems. The model is then manipulated and results are compared.

Simulation modeling assumes that we can describe a system in terms of acceptable parameters for a given computing system. In this regard, the key concept is the description of the state of the system. Assume that a system can be characterized by set of variables, with each combination of variable and their values representing a unique state or condition of the system, then manipulation of the variable values simulates movement of the system from state to state. A simulation experiment involves observing the dynamic behavior of a model by moving from state to state in accordance with well-defined operating rules designed into the model. Changes in the state of a system can occur continuously over time or at discrete instances in time. The discrete instants can be establish deterministically or stochastically depending on the nature of model inputs. Although the procedures for describing the dynamic behavior of discrete and continuous change model differ, the basic concept of simulating a system by portraying the changes in the state of the system over time remains the same (Pritsker 1986).

\section{LITERATURE ANALYSIS}

One study indicated that more K-12 students use their home computers for computer games than for school homework assignments (National Center for Educational Statistics, 2003). Clearly, computer and video animations are a part of the daily lives of students at the K-12 level (Simpson, 2005). These same students have expectations of their educational environment that include the nuances of the technical environment such as multimedia, and complex interactivity (Squire, Giovanetto, Devane \& Shree, 2005). Much like computer games, educational simulations and animations engage students in virtual worlds where they apply their knowledge, skills, and thinking in virtual situations (Gredler, 2004). Because learning in general, as well as how people learn is multidimensional (Gardner, Kornhaber, \& Wake, 1996), simulations and animations provide multi-sensory interaction, visualization, and symbols. Visualizations and symbols augment human cognitive capacities and help to convey concepts and information (Tversky, 2001). Much more effective than tutorials and drills, simulations enhance motivation, transfer of learning, efficiency, and flexibility while being safe, convenient, and controllable over real experiences (Alessi \& Trollip, 2001).

Successful educational simulations merge the engagement power of games with instructional content, and, these games are fun but not frivolous (Prensky, 2005). According to Prensky (2001), The United States Military spends in excess of $\$ 2$ billion a year on training. Much of the training provided to soldiers includes the use of technology and simulations for learning.

A number of internal validity studies were conducted in the early years of business gaming, comparing learning from games with learning from the case method within strategic management-type courses. The studies by Kaufman (1976), McKenney (1962; 1963), Raia (1966), and Wolfe \& Guth (1975) found superior results from game-based groups versus case groups either in course grades, performance on concept examinations, or goal setting exercises. Estes and Smith (1979) found superior game-related results in basic management and management ethics courses.

Dekkers and Donatti (1981) suggest that simulations have a positive effect on student motivation. Because they are actively involved, college students are engaged in the learning process rather than observers. Parente (1995) argues that simulations can "build an environment from which students can learn experientially". Therefore, college students analyze situations from the inside, or the position of a participant. By making students active learners, we motivate them to learn 
the material and succeed in the class. They also learn to view the material with a more critical eye as they make decisions themselves rather than passively accepting those made by others. Classroom simulations have been found to facilitate a deeper understanding of complex concepts (Dorn 1989; Dukes 2001; Jenkins 1992). Through reflection on direct experience, these exercises provide students with insights difficult to achieve through conventional pedagogical techniques.

Several advantages of instructional simulations have been discussed in the literature. Among the advantages, simulations have the potential to do the following: (1) Improve teaching aims and methods (Lederman, 1999; Baillie, 2000; Orrill, 2001 and Yeh, 2004). (2) Improve learning and practice (Baillie, 2000; Kneebone, 2000; Mangan, 2003; Boyd, 2004 and Turkle, 2004). (3) Motivate students (Reigeluth, 1989; Baillie, 2000; Yarger, 2003 and Mitchell, 2004). (4) Save operational cost and time (Lederman, 1999; Mangan, 2003 and West, 2005). (5) Increase safety (Mangan, 2003 and West, 2005).

\section{VIRTUAL REALITY}

Graphical animation has been of great benefit to simulation practitioners as a communication tool. Virtual reality, or virtual interface technology, a new technology that creates the illusion of an interactive three-dimensional environment, holds promise as the "next step" in the expanding simulation's role in communication. A joined software engineering project between the Human Interface Technology Laboratory and Auto Simulations, Inc., initiated to explore how virtual reality might impact simulations and to gain insight into bringing the technology to current educational and commercial simulation software packages. A manufacturing simulation program based on part of an actual factory's production line was constructed and both workers and managers from the facility were asked to evaluate the virtual factory. Auto Simulations' AutoMod and AutoView manufacturing simulation packages were chosen as the representative commercial system. Evaluation results were generally positive; however, there are more issues to be addressed before this exciting technology can be proven as the alternative to existing screen-based systems (Jones 1993).

Simulating manufacturing operations to check feasibility and efficiency is becoming common place in manufacturing. Low cost computer power makes comprehensive simulations affordable and software makers make them easier to create and watch. Simulations can put someone in a welding cell or a paint booth, for instance, to monitor the work of both human operator and the robot. One can take a bird's eye view of an assembly line as the assembly line runs in animation made, allowing users to interact with or change the virtual manufacturing environment (Owen 1995).

\section{BUILDING A GENERIC ANIMATION MODEL}

Since the main function of animation is to serve as communication tool, an animation needs to be visually accurate to a user. When presenting to managers, a visually accurate animation can increase the credibility of a simulation model and analysis. Currently, it is feasible to build a generic simulation model in a reasonable time period that gives to the user the capability of changing the system scope, the characteristics of the whole system or specific objects, and object names. The animation associated with the generic simulation must be able to display all of the changes made by a user in the simulation (Benjamin 1994).

This analysis covered a continuing effort to determine how animation is most effectively used for both model validation and model communication. It examined how to effectively use animation to display invalid model behavior. The invalid behavior displayed by each animation is a violation of an explicit model assumption. Two animation displays (moving icons and graphs) were evaluated individually and in combination at two different presentation speeds. The communication ability of each animated presentation was measured both subjectively and objectively. Objective measurements included the subject's identification accuracy for each violation and their response times. The results showed that moving icon animation was superior to the other two displays and that subjects identified violations sooner when the animation was shown at the slower of the two presentation speeds (Swider 1994).

The process for the successful development of a simulation model consists of beginning with a simple model which is embellished in an evolutionary fashion to meet the problem-solving requirements. Broadly speaking, the stages of a simulation project can be broken down into four major sections: Problem Definition, Model Building and Testing, Experimentation and Project Completion (see Figure 1). 


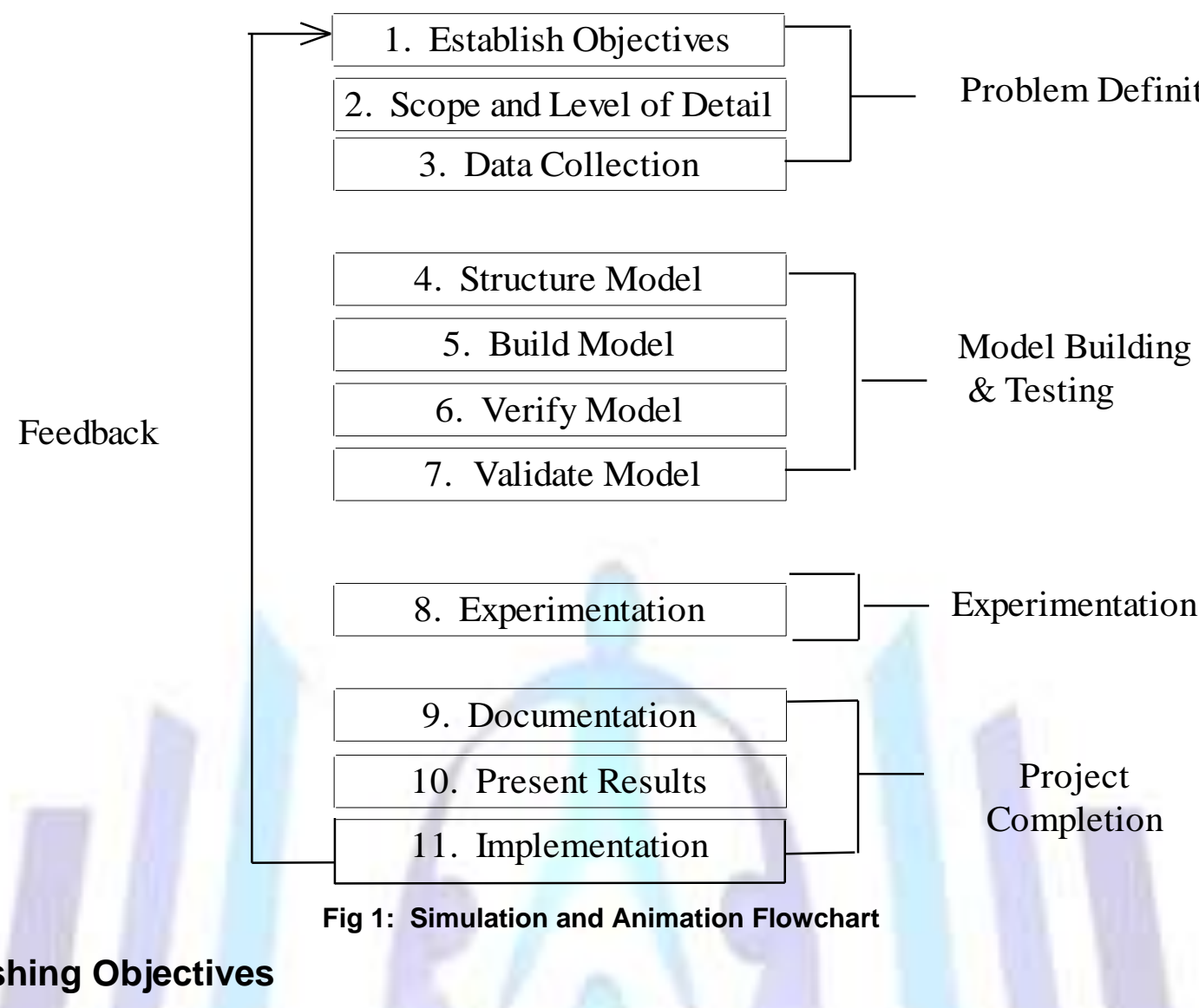

\section{Establishing Objectives}

The first step in any simulation project should be to set the objectives which is the statement of what should be achieved. Typical objectives may include: increase throughput and efficiency of the system. The objective should never be just to build a simulation model. There may also be some more general project objectives related to time scale, run speed or visual presentation.

The programming scope and level of detail determine what should be included in the model and to what detail. Bear in mind that it is important to begin modeling the minimum and which parameters are listed as the deterministic variables. More detail does not necessarily mean more accuracy.

\section{Model Building and Testing}

This section contains the structure of the model, building the model, verifying the model and validating the model. The testing of a simulation model should include verification and validation.

Whenever an estimate is used it should be declared as an assumption upon which the model is based. If the model later proves inadequate as a representation of the real world situation then assumptions upon which it was based may be placed under further scrutiny.

Prior to building the model, it is extremely useful to map out or structure how the model will look on paper. The structure or map of the model can help to get on overview of the whole model and map out any of the complex areas where further investigation is needed.

Model building should be approached by taking small steps at a time; coding, documenting and verifying. Before continuing onto the next step you should be confident that the step completed is working as intended. If this process is followed models are created with accuracy and are well documented. When finished, a complete self-explained simulation case is obtained.

\section{Model Verification and Validation}

The verification should consist of checking the code, inspecting output reports and checking that the elements modeled relate to the real world elements that they are representing. The correct behavior of the model needs to be verify by analyzing and verifying that every element in the simulated environment behaves as it is expected. In order to achieve this verification, statistics may be calculated and monitored temporarily during the process of structuring and developing the model and then removed from the final model as necessary.

A validation of the model should be performed upon completion of the model. This validation should test the overall accuracy of the model and the ability to meet the project objectives. This phase helps to establish credibility by giving confidence in the results. 
There are various ways in which the model can be validated. One technique is to run the model and ask an expert to validate the performance of the model. In comparing the model to the real system, the results produced can be compared to historical data. Results from the real system and results from the model could be evaluated and compared. The model produced could also be compared to other models: mathematical models, deterministic models and other simulation models.

\section{Experimentation}

When you are satisfied that the model closely approximates the behavior of the real-life situation a number of what-if scenarios may be investigated. The scenarios to be investigated should have been defined within the original objectives of the simulation study. Successful experimentation typically involves using a warm-up period or starting conditions, deciding on a suitable run-length, and running the model with more than one random number stream.

A warm-up period may be necessary to allow the model to reach a steady-state before results are collected. For example, it is highly unlikely that a production line would be completely empty of parts first thing on a Monday morning though the computer simulation would start from such state. A warm-up period of say a week would allow stocks to build up to a typical level. You could then instruct the model to disregard the results of the first week and start to collect statistics from Monday morning of the second week. It is possible to specify a warm-up period from the Model $\backslash$ Options $\backslash$ Detail menu or from the Experiment menu.

A possible alternative to a warm-up period is to include some starting conditions within the model. At time zero parts are dispatched to various elements. The number of parts and their destinations correspond to a typical work-in-progress situation. There is now no need for a warm-up period as the model is being run from a typical real-life situation. Starting conditions may be created using active part arrivals or dummy starting condition machines which process large numbers of parts at time zero but are then made inactive for the remainder of the simulation.

Although most simulation runs require either warm-up periods or starting conditions, some situations do not need either. For example, a model built to study customer service levels at a bank would preferably start from an empty state since banks do find themselves in that situation as they open their doors each morning.

Any experiment involves running a model for a specified length of time under different circumstances. The length of the run should be determined by a number of factors. The most important factor is that a reasonable sample of random numbers is taken from each of the random number streams used in the model. Each run should aim to use at least 10-15 numbers from each stream. If one stream is being used to calculate a breakdown interval of between 1 and 2 weeks then a run length of between 20 and 30 weeks would be necessary.

Another factor is the reporting period of the real-life situation being modeled. It makes little sense to calculate an optimum run length of 3 weeks and 1 day if you need to compare your model results with a real-life situation which reports every 30 day period.

It is important to run any model with random activity using several random number streams before any confidence is placed in the model's results. Otherwise it is possible that the results obtained are solely the consequence of the random number stream chosen rather than any model changes made by the user. The number of runs required varies with the number of incidences of randomness within the model but a good rule of thumb is to run each variation of the model using the same four to five random number streams.

Facilities to change random streams exist under the Model\Random Numbers pull-down menu. Or the running of a model using a number of streams may be automated using the Experiment menu.

Upon completion of the project, a number of tasks may need to be done. These include complete documentation, communicate results, prepare report and implement the recommendations. It is also useful, at the end of a simulation project, to review the overall project process and perhaps refine the process prior to starting the next project (AT\&T ISTEL 1995).

It is a good idea to document the building of a model to facilitate its further use by a user at a later date. Such documentation should include the model structure diagram.

The sources of data used, the assumptions made and the results obtained should also form part of the model documentation. If the project is documented as it proceeds then the documentation will prove to be a less complex and onerous task. It is recommended that any project documentation is completed before the presentation of results as there is often less inclination to document a project which has been laid to rest.

\section{CONCLUSION}

Undergraduate and graduate courses in simulation can serve their students and the industry by teaching and integrating animation as part of the simulation classes. The teaching process should include application and utilization of the results. The process of experimentation using simulation and animation and the verification of the output through practical and analytical techniques are an essential part of the educational process.

\section{REFERENCES}

[1] Alternatives, Journal of Industrial Engineering, 18-19. 
[2\} AT\&T ISTEL 1995, Introduction to Witness

[3] Baillie, C. and Percoco G. (2000). A Study of Present Use and Usefulness of Computer-Based Learning at a Technological University. European Journal of Engineering Education. 25, 33-43.

[4] Collins, M.J. 1995, Benchmarking with simulation: how it can help your production operations, Production Journal, 50- 52.

[5] Dekkers, J. and S. Donati The integration of research studies on the use of simulation as an instructional strategy. Journal of Educational Research (1981) 74: 424-7.

[6] Dorn, D. Simulation Games: One more tool on the pedagogical shelf. Teaching Sociology (1989) 17: 1-18.

[7] Dukes, R. ed. Simulation and Gaming and the Teaching of Sociology 8th ed. Washington, DC: American Sociological Association. (2001).

[8] Gardner, H., Kornhaber, M., \& Wake, W. (1996). Intelligence: Multiple perspectives. Fort Worth, TX: Harcourt Brace.

[9] Gredler, M. E. (2004). Games and simulations and their relationships to learning. In Jonassen, D. H. (2004) Handbook of Research on Educational Communications and Technology. (pp. 571-583). Mahwah, NJ: IEA Publications.

[10] Hurrion. RD 1986, Engineering Journal of Operations Research, Vol.23, Industrial Engineering Magazine May 94, 58 -71

[11] Jenkins, A. Active Learning in Structured Lectures. in: Teaching large classes in higher education. Edited by Graham Gibbs and Alan Jenkins. (1992), pp. 63-77 London, England: Kogan Page.

[12] Kaufman, F.L. (1976) An empirical study of the usefulness of a computer-based business game. Journal of Educational Data Processing, 13 (1): 13-22.

[13] Lederman, N. and Niess M. (1999). Is It Live or Is It Memorex. School Science \& Mathematics. $357-359$.

[14] McKenney, J.L. (1962) An evaluation of business game in an MBA curriculum. Journal of Business, 35: 278-286.

[15] McKenney, J.L. (1963) An evaluation of a decision simulation as a learning environment. Management Technology, 3 (1): 56-67.

[16] Orrill, C. (2001). Building Technology-Based Learner-Centered Classrooms: The Evolution of a Professional Development Framework. Educational Technology Research and Development. 49, 15-34.

[17] Owen V. Jean 1995, Manufacturing Engineering.

[18] Parente, D. H. A large-scale simulation for teaching business strategy. In: Simulation and gaming across disciplines and cultures, ed. D. Crookall and K. Arai, (1995) pp.75-82. Thousand Oaks, CA: Sage publishers.

[19] Prensky, M. (2001). Digital natives, digital immigrants. In On the Horizon. NCB University Press, 9 (5), 66-84. Prensky, M. (2005). What can you learn from a cell phone? Almost anything! Innovate: Journal of Online Education, 1(5), 37-42.

[20] Pristker B. Alan 1986, Introduction to Simulation and SLAM II, John Wiley

[21] Raia, A.P. (1966) A study of the educational value of management games. Journal of Business, 39: 339-352.

[22] Simpson, E. S. (2005). What teachers need to know about the video game generations. Tech Trends: Journal of the Association for Educational Communications and Technology. 49 (5), 17-22.

[23] Squire, K., Giovanetto, L., Devane, B., \& Shree, D, (2005). From users to designers: Building a self-organizing game -based learning environment. Tech Trends: Journal of the Association for Educational Communications and Technology. 49 (5), 34-42.

[24] Turkle, S. (2004). How Computers Change the Way We Think. Chronicle of Higher Education. 50, 26-28.

[25] Tversky, B. (2003). Navigating by mind and by body. In C. Freksa, C., Brauer, W., Habel, C and Wender, K. F. (EDs.), Spatial cognition II: Integrating abstract theories, empirical studies, formal methods, and practical applications. Pp. 72- 79. N.Y.: Springer.

[26] West, R, and Graham, C. R. (2005). Five Powerful Ways Technology can Enhance Teaching and Learning in Higher Education. Educational Technology. 45 (3), 20-27.

[27] Wolfe, J. \& Guth, G. (1975) The case approach vs. gaming in evaluation. Journal of Business, 48(3): 349-364. 